Pistor-Hatam

Iran und die Reformbewegung im Osmanischen Reich 
ISLAMKUNDLICHE UNTERSUCHUNGEN · BAND 158

\author{
begründet \\ von \\ Klaus Schwarz \\ herausgegeben \\ von \\ Gerd Winkelhane
}


ISLAMKUNDLICHE UNTERSUCHUNGEN · BAND 158

Anja Pistor-Hatam

Iran und die Reformbewegung

im Osmanischen Reich

Persische Staatsmänner, Reisende und

Oppositionelle unter dem Einfluß der Tanẓimāt 
Die Deutsche Bibliothek - CIP-Einheitsaufnahme

\section{Pistor-Hatam, Anja:}

Iran und die Reformbewegung im Osmanischen Reich : persische Staatsmänner, Reisende und Oppositionelle unter dem Einfluss der Tanẓimāt / Anja Pistor-Hatam. - Berlin : Schwarz, 1992

(Islamkundliche Untersuchungen ; Bd. 158)

Zugl.: Freiburg (Breisgau), Univ., Diss., 1992

ISBN 3-87997-200-1

NE: GT

Alle Rechte vorbehalten.

Ohne ausdrückliche Genehmigung des Verlages

ist es nicht gestattet, das Werk oder einzelne Teile daraus

nachzudrucken oder zu vervielfältigen.

(c) Gerd Winkelhane, Berlin 1992.

Klaus Schwarz Verlag GmbH, Bergstraße 2, D-1000 Berlin 41

ISBN 3-87997-200-1

Druck: Offsetdruckerei Gerhard Weinert GmbH, D-1000 Berlin 42 